\title{
COVID-19 and the role of health promoters and educators
}

\section{[version 1; peer review: 1 approved with reservations, 1 not approved]}

James Woodall (iD)

Leeds Beckett University, Leeds, United Kingdom

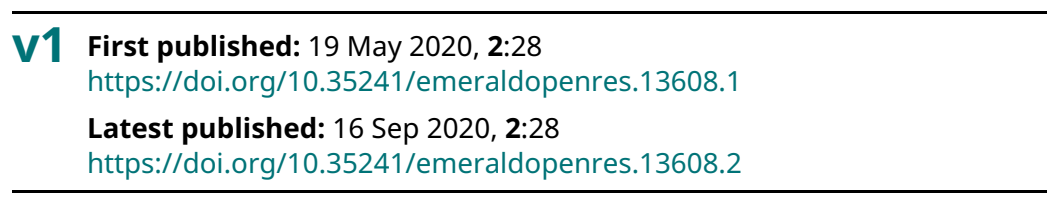

\section{Abstract}

The role of health promoters and educators in the current and future response to COVID-19 is critical, but, to date, under explored. This opinion paper offers a number of important contributions that this professional group may offer both in the immediate and future strategy of global public health. While the importance of a medical model of health cannot be underplayed, the social model of health suggests that some groups in society are being more disproportionately impacted than others. Health promotion has been committed to reducing inequalities and therefore offers 'a voice' to those most marginalised. The paper suggests that bottom-up approaches focusing on building individual and community control is essential and, moreover, the concepts of a settings approach in health promotion, the fostering of critical health literacy and 'salutogenesis' may be worthy of further debate and discussion.

\section{Keywords}

COVID-19, health promotion, health education, social model, salutogenesis

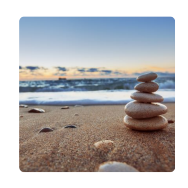

This article is included in the Healthier Lives gateway.

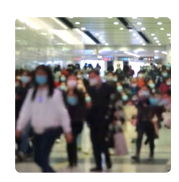

This article is included in the Coronavirus (COVID-19) collection.

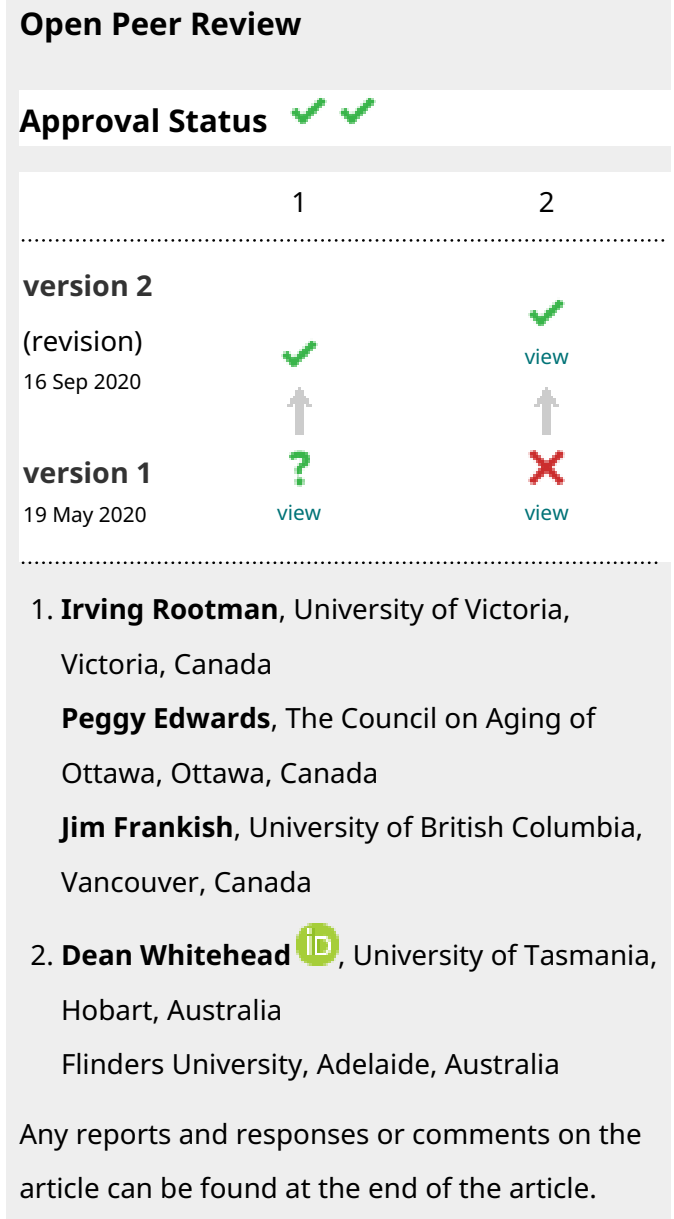


Corresponding author: James Woodall (j.woodall@leedsbeckett.ac.uk)

Author roles: Woodall J: Conceptualization

Competing interests: No competing interests were disclosed.

Grant information: The author(s) declared that no grants were involved in supporting this work.

Copyright: (c) 2020 Woodall J. This is an open access article distributed under the terms of the Creative Commons Attribution License, which permits unrestricted use, distribution, and reproduction in any medium, provided the original work is properly cited.

How to cite this article: Woodall J. COVID-19 and the role of health promoters and educators [version 1; peer review: 1 approved with reservations, 1 not approved] Emerald Open Research 2020, 2:28 https://doi.org/10.35241/emeraldopenres.13608.1

First published: 19 May 2020, 2:28 https://doi.org/10.35241/emeraldopenres.13608.1 


\section{Introduction}

The global health challenges that have been posed by COVID-19 have been far-reaching, devastating and tragic. The huge cost to society, communities and families will not be rehearsed here, as all readers will be familiar with the implications, both personally and professionally. This short opinion piece, with the hope of stimulating debate and dialogue, suggests that health promoters and educators have a critical role in the current and future response to this pandemic but have so far been slow to respond.

Health promoters have always aligned themselves to a social model of health, but this is a time to see the great benefits of a medical model and how important well-supported and funded health systems are when such a pandemic hits. Moreover, the importance of public health, sometimes underappreciated in some countries, is now seen as being critical in all aspects of COVID-19.

Public health is a broad term and a useful starting point is to perhaps disentangle health promotion and disease prevention - its two primary constituents. While some conceptual models draw clear distinctions between the two (Green et al., 2019), there is often some ambiguity. Within public health efforts, disease prevention activities are currently being actively employed to protect public health globally. Surveillance measures; policy enforcing self-quarantine; the closure of schools, restaurants and cinemas; the insistence for people to stay at home; and testing and screening measures, are just a few examples. Health promotion, on the other hand, can be seen as focussing primarily on advancing individuals towards the positive end of the disease-health continuum (Breslow, 1999; Brubaker, 1983; King, 1994). Nutbeam (1986: 115), for example, draws an important distinction between health promotion and disease prevention. He suggests:

"Disease prevention is essentially an activity in the medical field dealing with individuals or particularly defined groups at risk. It aims to conserve health. It does not represent a positive vision of health that moves ahead, but is concerned with maintaining the status quo. Health promotion on the other hand, starts out with the whole population in the context of their everyday lives, not selected individuals or groups. Its goal is to enhance health."

What though, can health promoters and educators - focusing on more positive conceptualisations of health - contribute during this pandemic. To date, the response has been slow, but evidence has shown that health promoters play a critical role in pandemics (Laverack \& Manoncourt, 2016). The following paragraphs offer some conceptual and practical suggestions both for the immediate and longer-term.

\section{Contribution of health promoters}

Glenn Laverack outlined specifically the key contribution that health promotion can make in emergency outbreaks - citing the potential contribution both before, during and after (Laverack, 2017). Health promotion as a practice and discipline is suggested to be well-placed to use 'bottom-up', grass-roots approaches to engage individuals and communities in the delivery of the response (Laverack \& Manoncourt, 2016). Indeed, we have seen how critical strong and active communities have been - both physically and digitally - in keep people safe and in supporting individual and community well-being. The examples of this in communities across the world have been endless. The active participation of people supporting each other has been a cornerstone of health promotion values for over thirty years (WHO, 1986). Evidence suggests that individuals have a better chance of achieving their health goals if they can share these matters with other people who are faced with similar problems (Woodall et al., 2010) - the rise in people connecting digitally to share experiences and to offer companionship has been so important for many. Through participation, individuals are likely to experience some degree of control as they are better able to define and analyse their concerns, and together they are capable of finding joint solutions to act on their issues (Laverack, 2005). Health promoters are uniquely placed to facilitate and support these efforts, actively contributing to individuals feeling a greater sense of control over their circumstances.

\section{Salutogenesis}

In addition to community participation, a further key idea in health promotion is the notion of salutogenesis. There is no doubt that a focus on pathogenesis is absolutely fundamental during COVID-19 and the role of disease prevention central (as noted earlier). During this challenging time, however, it may also be important not to lose sight of the question 'what makes people healthy?' or what is the origin of health, as this one of the critical pillars of salutogenisis (Mittelmark \& Bauer, 2017). Antonovsky (1996) studied the question of what creates health. His answer was formulated in terms of the sense of coherence (SOC) and generalized resistance resources (GRR). The SOC consists of three dimensions: comprehension, manageability and meaningfulness, reflecting the interaction between the individual and the environment. GRR are factors that can support a person or community to cope effectively - they can include various factors, for instance material resources (e.g., money), genetic (e.g., intelligence), knowledge (e.g., coping strategies), and social (e.g., social network). Both SOC and GRR interplay to support individuals' health. This brings us to health promotion and education's fundamental quest to reduce health inequalities and to consider how COVID-19 may be impacting disproportionately on people's SOC and GRR. For example, those in manual jobs may be financially impacted during lockdown when it is impossible to work at home; moreover, those living in high-rise buildings may be affected more acutely than those with access to green spaces. How the health promotion and education community supports these groups now and when the recovery post-COVID commences is fundamental to ensure that these groups are not further marginalised.

\section{Healthy settings approach}

The notion of healthy settings is one that has been popular with health promoters and educators and may be a legitimate and practical way to address the inequalities as a result of COVID-19. The key idea of the settings approach, or healthy settings approach, is that investments in health are made in social systems where 
health is not their primary remit. The settings approach has been criticised for not being joined-up in its approach (Woodall \& Freeman, 2020). Any effective activity is ensured when settings 'join-up' and work mutually to ensure holistic and integrated activities. This pandemic has perhaps amplified frailties in settings working together - how health messages from schools to homes are communicated for example or how health activities are managed and co-ordinated in environments where people live in close-proximity (prisons, care homes etc.). The idea of holistic working across systems and institutions now seems the only way forward to ensure public health is fully protected.

\section{Critical health literacy}

Finally, at the present time, scholars have noted the importance of health communication during COVID-19 and the importance of critical health literacy (Abel \& McQueen, 2020). Indeed, the continuous news, politician briefings and endless commentary on digital platforms creates information-overload and confusion at best and, at worst, panic and anxiety for many (Abel \& McQueen, 2020). There are several examples where untrustworthy sources have caught the public imagination and have provided illegitimate concerns (Shimizu, 2020). Health educators are essentially placed to translate this information into credible sources to promote public understanding and provide accurate and timely information in culturally specific ways. Explanations to children, as one example, is important and health educators could be ideally situated to support parents in their support of their child's psychological well-being (Wang et al., 2020).

\section{Conclusions}

We are in unprecedented times in relation to global health. The immediate threat posed by COVID-19 has seen epidemiologists, scientists and politicians coming together to evaluate how best to manage and control this pandemic. This short piece has suggested that health promotion has been slower to react but that health promoters and educators can make a significant contribution to the current and future issues that emerge from this public health crisis.

\section{Data availability}

No data are associated with this article.

\section{References}

Abel T, McQueen D: Critical health literacy and the COVID-19 crisis. Health Promot Int. 2020; pii: daaa040.

PubMed Abstract | Publisher Full Text | Free Full Text

Antonovsky A: The salutogenic model as a theory to guide health promotion. Health Promot Int. 1996; 11: 11-18.

Publisher Full Text

Breslow L: From disease prevention to health promotion. JAMA. 1999; 281: 1030-1033.

PubMed Abstract | Publisher Full Text

Brubaker BH: Health promotion: a linguistic analysis. ANS Adv Nurs Sci. 1983; 5(3): 1-14

PubMed Abstract | Publisher Full Text

Green J, Cross R, Woodall J, et al.: Health promotion. Planning and strategies. London: Sage. 2019.

Reference Source

King PM: Health promotion: the emerging frontier in nursing. $J$ Adv Nurs. 1994 20(2): 209-218.

PubMed Abstract | Publisher Full Text

Laverack G: Public health. Power, empowerment and professional practice.

Basingstoke: Palgrave. 2005.

Reference Source

Laverack G: Health promotion in disease outbreaks and health emergencies. London: CRC Press. 2017.

Reference Source

\author{
Laverack G, Manoncourt E: Key experiences of community engagement and \\ social mobilization in the Ebola response. Glob Health Promot. 2016; 23(1): \\ 79-82. \\ PubMed Abstract | Publisher Full Text \\ Mittelmark MB, Bauer GF: The meanings of salutogenesis. In: The handbook of \\ salutogenesis. Springer, Cham, 2017; 7-13. \\ PubMed Abstract | Publisher Full Text \\ Nutbeam D: Health promotion glossary. Health Promot. 1986; 1: 113-127. \\ PubMed Abstract | Publisher Full Text \\ Shimizu K: 2019-nCoV, fake news, and racism. Lancet. 2020; 395(10225): \\ $685-686$. \\ PubMed Abstract | Publisher Full Text | Free Full Text \\ Wang G, Zhang Y, Zhao J, et al:: Mitigate the effects of home confinement on \\ children during the COVID-19 outbreak. Lancet. 2020; 395(10228): 945-947. \\ PubMed Abstract | Publisher Full Text | Free Full Text \\ WHO: Ottawa Charter for health promotion. Health Promot. 1986; 1: iii-v. \\ Reference Source \\ Woodall J, Freeman C: Where have we been and where are we going? The state \\ of contemporary health promotion. Health Educ J. 2020. \\ Publisher Full Text \\ Woodall J, Raine G, South J, et al: Empowerment \& health and well-being: \\ evidence review. Leeds: Centre for Health Promotion Research, 2010; Leeds \\ Metropolitan University. \\ Reference Source
}




\section{Open Peer Review}

\section{Current Peer Review Status: ? X}

\section{Version 1}

Reviewer Report 02 July 2020

https://doi.org/10.21956/emeraldopenres.14679.r26945

(C) 2020 Whitehead D. This is an open access peer review report distributed under the terms of the Creative Commons Attribution License, which permits unrestricted use, distribution, and reproduction in any medium, provided the original work is properly cited.

\section{Dean Whitehead}

1 University of Tasmania, Hobart, Australia

2 Flinders University, Adelaide, Australia

Overall, this is a reasonably well articulated 'opinion' piece. The author is well known in this field and cites a number of eminent authors. I have a few reservations in it's current form.

These being:

1. The topic will be fine if it is aimed at raising awareness with a 'general' redership audience that may not be overly familiar with health promotion and health education processes. However, if the eventual audience were - this would not report much that is not already known and have been established 'issues' within the disciplines pre-Covid as well.

2. In my mind, opinion pieces are best (and safest) with at least two authors.

3. Parts of the text can read as 'notation form' i.e. statement/citation - followed immediately by another statement/citation - especially the health literacy section.

4. I would argue that the two sections on 'settings' and 'health literacy' are too brief. This is easily rectified as there are a number of statements that do not expand on what they are reporting i.e. "There are several examples where untrustworthy sources have caught the public imagination and have provided illegitimate concerns (Shimizu, 2020)." - what examples, why, how?

I hope that these comments assist.

Is the topic of the opinion article discussed accurately in the context of the current literature?

Yes

Are all factual statements correct and adequately supported by citations? Yes 
Are arguments sufficiently supported by evidence from the published literature? Partly

Are the conclusions drawn balanced and justified on the basis of the presented arguments? Partly

Is the argument information presented in such a way that it can be understood by a nonacademic audience?

Partly

Does the piece present solutions to actual real world challenges?

Partly

Is real-world evidence provided to support any conclusions made?

Partly

Could any solutions being offered be effectively implemented in practice?

Partly

Competing Interests: No competing interests were disclosed.

Reviewer Expertise: Clinical health promotion and health education theory, practice and policy

I confirm that I have read this submission and believe that I have an appropriate level of expertise to state that I do not consider it to be of an acceptable scientific standard, for reasons outlined above.

Reviewer Report 08 June 2020

https://doi.org/10.21956/emeraldopenres.14679.r26822

(C) 2020 Rootman I et al. This is an open access peer review report distributed under the terms of the Creative Commons Attribution License, which permits unrestricted use, distribution, and reproduction in any medium, provided the original work is properly cited.

Irving Rootman

School of Public Health and Social Policy, University of Victoria, Victoria, BC, Canada

Peggy Edwards

The Council on Aging of Ottawa, Ottawa, Canada

Jim Frankish

University of British Columbia, Vancouver, Canada

This is a timely short opinion article on the contribution of health promoters and educators in response to the COVID-19 pandemic, guided by three key concepts in the field of health promotion, namely, salutogenesis, the healthy settings approach and critical health literacy. 
In our opinion, this article is an excellent start on developing a framework for defining the role of health promoters and educators in relation to epidemics and is worthy of publication as is.

That being said, here is one revision we would recommend. That is the reference to "the medical model" in the Introduction. The medical model is undefined and appears to be in opposition to the social model of health. In fact, a social model of health includes access to universal quality healthcare (that include a robust public health system). Perhaps the sentence could be modified to say: "Health promoters have always aligned themselves with a social model of health. The Covid 19 pandemic has reminded us that this must include access to universal, well-supported and well-funded healthcare systems (including a robust public health system) as well as the other determinants of health in the broad socioeconomic environment (e.g. income. education, social support).

By focussing on just three useful concepts in health promotion (perhaps due to the need to be brief) the piece points to the need to address some additional issues. One critical issue is who should be considered to be a "health promoter" or "health educator"? Is a health promoter someone that does something that results in improvement of somebody's health or the health of an organization or a community. Similarly, is a "health educator" someone who teaches individuals or groups how to improve their health or the health of an organization or community? Or is a "health promoter" someone that has studied "health promotion" and received a diploma or degree in "health promotion" or "health "education"? Clearly, this is a matter for debate that has not yet been totally resolved. At minimum, it seems as if the author is suggesting that it might be someone who understands the concepts of salutogenesis, the healthy settings approach and critical health literacy, and knows how to apply them in practice.

If this is the case, we would like to suggest that there are other concepts in health promotion and health education that are particularly relevant to promoting health in a pandemic and its aftermath. .

For example, we suggest that not only is critical health literacy relevant to addressing the current pandemic and future epidemics, but so are other kinds of health literacies. As we have learned from the increased use of digital technologies to connect during the current pandemic , "digital health literacy" defined by Norman and Skinner (2006b) ${ }^{1}$ as "the ability to seek, find, understand, and appraise health information from electronic sources and apply the knowledge gained to addressing or solving a health problem" has become an essential skill.

The same is likely true for functional health literacy (sufficient basic skills in reading) given that people that can read are more likely to be able to understand or solve problems on their own. Similarly, people who have "interactive health literacy" skills (more advanced cognitive and literacy skills and social skills) that allows them to understand information and derive meaning from different forms of communication, and to apply new information to changing circumstances" (Nutbeam, 2000) $)^{2}$ certainly will fare better in a pandemic.

Another health promotion concept that is used frequently by academics and practitioners in health promotion work is "action areas". The following such areas or strategies are enshrined in the Ottawa Charter for Health Promotion: Build Healthy Public Policy; Create Supportive Environments; Strengthen Community Action; Develop Personal Skills; and Reorient Health Services. The opinion article mentions actions related to creating supporting environments, 
strengthening community action, and developing personal skills to which health promotion and education has, or could contribute. We think that COVID-19 has also stimulated the need for action on building healthy public policy and reorienting health services. Health promoters and educators, however defined, could also make a significant contribution in these two action areas An example of a proposal for such a policy stimulated by COVID-19 can be found in a recent article in the Journal of Medical Internet Research (Katapally, T.R., 2020) ${ }^{3}$.

Finally, two other concepts that are fundamental to health promotion and other health and nonhealth fields of practice that have been particularly important in assessing the implications of COVID-19 are "equity "and "determinants of health". For example. a recent British study found that "greater proportions of residents from ethnic minority backgrounds had statistically significantly higher COVID 19 mortality rates, as did local authorities with a greater proportion of residents experiencing deprivation relating to low income" (Rose, et al., 20204) While the author mentions the health promotion goal of recusing inequalities in the section on salutogenesis, it could be made clearer that equity needs to be a fundamental value in responding to pandemics. The author also makes reference in this section to the "need for material and social resources." This could be more strongly and clearly discussed under the importance of the concept "determinants of health" ( which is well known and central to health promotion) when responding to pandemics.

In the end, it falls to proponents of health promotion to better address the above issues; if they wish to position health-promotion strategies as viable tools for addressing pandemics. Health promotion can complement and strengthen public and population health efforts. It has a rich history of enacting a comprehensive range of strategies that are well placed to deal with complex challenges like COVID-19.

\section{References}

1. Norman CD, Skinner HA: eHealth Literacy: Essential Skills for Consumer Health in a Networked World.J Med Internet Res. 2006; 8 (2): e9 PubMed Abstract | Publisher Full Text

2. Nutbeam D: Health literacy as a public health goal: a challenge for contemporary health education and communication strategies into the 21st century. Health Promotion International. 2000; 15 (3): 259-267 Publisher Full Text

3. Katapally T: A Global Digital Citizen Science Policy to Tackle Pandemics Like COVID-19. Journal of Medical Internet Research. 2020; 22 (5). Publisher Full Text

4. Rose T, Mason K, Pennington A, McHale P, et al.: Inequalities in COVID19 mortality related to ethnicity and socioeconomic deprivation. medRxiv. 2020. Publisher Full Text

Is the topic of the opinion article discussed accurately in the context of the current literature?

Partly

Are all factual statements correct and adequately supported by citations? Partly

Are arguments sufficiently supported by evidence from the published literature? Partly

Are the conclusions drawn balanced and justified on the basis of the presented arguments? 
Partly

Is the argument information presented in such a way that it can be understood by a nonacademic audience?

Partly

Does the piece present solutions to actual real world challenges?

Partly

Is real-world evidence provided to support any conclusions made?

Partly

Could any solutions being offered be effectively implemented in practice?

Partly

Competing Interests: No competing interests were disclosed.

Reviewer Expertise: Health Promotion, Health Literacy

We confirm that we have read this submission and believe that we have an appropriate level of expertise to confirm that it is of an acceptable scientific standard, however we have significant reservations, as outlined above. 